\title{
La funció del disseny en els processos d'innovació*
}

\author{
Anna Estany \\ UNIVERSITAT AUTÒNOMA DE BARCELONA \\ anna.estany@uab.cat \\ Rosa M. Herrera \\ ICAI (ESCUELA TÉCNICA SUPERIOR DE INGENIERÍA) \\ herrera.rm民gymail.com
}

Rebut: 28/04/2020

Acceptat: 30/07/2020

\section{RESUM}

Hi ha paraules que, en un moment determinat, emergeixen com a catalitzadores d'idees que prèviament havien tingut altres sentits. Entre elles estan «innovació» i «disseny». La innovació ha estat tradicionalment associada a la ciència aplicada, especialment a la tecnologia, mentre que els canvis en les ciències pures se solien catalogar com a descobriments, invencions o creacions sense més ni més. No obstant això, des de fa unes dècades, la innovació s'ha endinsat en tots els àmbits del coneixement científic, tant en les ciències pures com en les aplicades. També el disseny ha eixit del nínxol on havia romàs durant dècades i fins i tot centúries, almenys pel que fa a la història de la filosofia i de la ciència. De fet, a mesura que s'ha anat introduint en el món acadèmic ha estat molt lligat a l'art i aplicat a entorns de la nostra vida quotidiana. L'objectiu d'aquest article és analitzar els processos d'innovació en les ciències pures i aplicades, veient fins a quin punt les teories de disseny sorgides en les últimes dècades han influït en la innovació de camps com l'epistemologia i la tecnologia. Ens centrarem en l'epistemologia de disseny i en la innovació metodològica, en concret en la simulació i els models metodològics de disseny. Prendrem com a referència tant les ciències pures o descriptives com les aplicades o de disseny, a més de la tecnologia subjacent a ambdós camps i amb un paper molt rellevant en els processos d'innovació.

Paraules clau: epistemologia de disseny, innovació, simulació computacional, model metodològic.

\section{ABSTRACT. Design Function in Innovation Processes}

Some words emerge at a given moment to catalyse ideas and give new meaning to old terminology. Innovation and design are two such words. Innovation has traditionally been linked with the Applied Sciences, especially technology, whereas advances in the Pure Sciences tend to be termed discoveries, inventions, or creations. However, for decades now, innovation has been a leitmotiv in all fields of scientific knowledge in both the Pure and the Applied Sciences. Design has also emerged from the niche it once occupied for decades (and even centuries) at least insofar as its impact on the History of Science and of Philosophy is concerned. In fact, design's introduction into the academic world has gone hand-in-hand with Art and its impact on our daily lives. This paper analyses innovation processes in both the Pure and the Applied Sciences to discover how far new design theories over the last few decades have influenced innovation in fields such as Epistemology and Technology. We focus on Design Epistemology and methodological innovation, specifically in connection with design simulations and methodological models. We also look at the underlying design technologies and the key role they play in innovation processes.

Keywords: Design epistemology, innovation, computer simulation, methodological model.

\footnotetext{
*Aquest treball ha sigut finançat pel Ministeri de Ciència, Innovació i Universitats dins del Subprograma Estatal de Generació del Coneixement per mitjà del projecte d'investigació FFI2017-85711-P «Innovación epistémica: el caso de las ciencias biomédicas». Aquest treball forma part de la xarxa d'investigació consolidada «Grupo de Estudios Humanísticos de Ciencia y Tecnología» (GEHUCT), reconeguda i finançada per la Generalitat de Catalunya, referència 2017 SGR 568.
} 


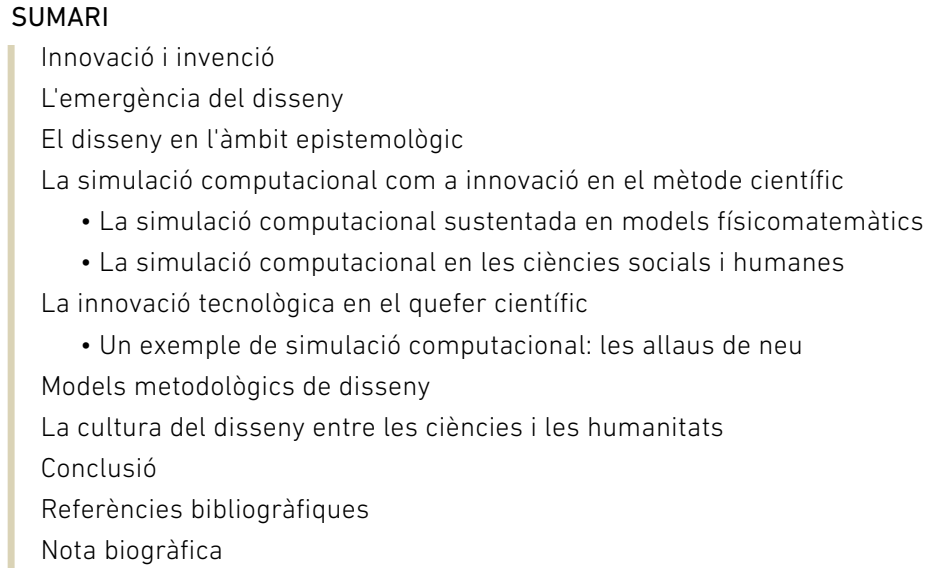

Autora per a correspondència / Corresponding author: Anna Estany. Departament de Filosofia. Edifici B. Campus de la UAB. 08193 Bellaterra. Cerdanyola del Vallès (Espanya).

Citació suggerida / Suggested citation: Estany, A. i Herrera, R. M. (2021). La funció del disseny en els processos d'innovació. Debats. Revista de cultura, poder i societat, 135(2), 53-67. DOI: http://doi.org/10.28939/iam.debats-135-2.4

Hi ha paraules que, en un moment determinat, emergeixen com a catalitzadores d'idees que prèviament havien tingut altres sentits. Entre elles estan «innovació» $\mathbf{i}$ «disseny». La innovació ha estat tradicionalment associada a la ciència aplicada, especialment a la tecnologia, mentre que els canvis en les ciències pures se solien catalogar com a descobriments, invencions o creacions sense més ni més. No obstant això, des de fa unes dècades, la innovació s'ha endinsat en tots els àmbits del coneixement científic, tant en les ciències pures com en les aplicades (Estany i Herrera, 2016).

També el disseny ha eixit del nínxol on havia romàs durant dècades i fins i tot centúries, almenys pel que fa a la història de la filosofia i de la ciència. De fet, a mesura que s'ha anat introduint en el món acadèmic, ha estat molt lligat a l'art i aplicat a entorns de la nostra vida quotidiana. Determinar amb precisió el canvi de tendència en aquest tema no és una tasca gens fàcil, però possiblement la revolució industrial, l'expansió dels productes a segments amplis de la població i la producció en sèrie poden considerar-se factors que han incentivat la introducció del disseny en tots els àmbits del coneixement.

L'objectiu d'aquest article és analitzar els processos d'innovació en les ciències pures i aplicades per veure fins a quin punt les teories de disseny sorgides en les últimes dècades han influït en la innovació de camps com l'epistemologia i la tecnologia. No hi ha dubte que la innovació pot abordar-se des de moltes perspectives i des de moltes disciplines, però ens centrarem en la relació entre innovació i disseny. D'una banda, ens centrarem en l'epistemologia de disseny com una nova perspectiva que comporta innovació en el camp epistemològic; de l'altra, en la innovació metodològica, en concret, en la simulació i els models metodològics de disseny. Per a analitzar aquestes dues qüestions prendrem com a referència tant les ciències pures o descriptives com les aplicades o de disseny. Darrere d'aquests camps científics està la tecnologia, que té un paper molt rellevant en els processos d'innovació. Per tant, 
caldrà veure el paper del disseny en la innovació tecnològica i com aquesta es plasma en els artefactes $i$ en el modelatge de sistemes.

En primer lloc, donarem un panorama de les principals característiques dels conceptes d'innovació i invenció; en segon, veurem com el disseny ha penetrat en diversos àmbits de coneixement $i$ analitzarem l'epistemologia del disseny i els conceptes relacionats amb aquesta; en tercer lloc, analitzarem el paper de les simulacions en la investigació científica com a innovació epistemològica i l'aplicació que té a casos pràctics; en quart lloc, exposarem l'esquema de McCrory sobre metodologia de disseny a partir de les propostes de Herbert Simon en l'obra Las ciencias de lo artificial (1996) i del filòsof Ilkka Niiniluoto sobre les ciències de disseny que exposa en l'article «The aim and structure of applied sciences» (1993); i finalment, proposarem una cultura de disseny com a marc per a un abordatge integral dels processos d'invenció i innovació. Cal tindre en compte que totes aquestes qüestions podrien ser motiu d'un sol article, però van més enllà dels propòsits d'aquest treball. També cal dir que els autors de referència són solament alguns entre molts altres, però s'ha considerat que allò nuclear és la temàtica per a la qual es proposen una sèrie d'autors rellevants per a les qüestions plantejades.

\section{INNOVACIÓ I INVENCIÓ}

D'alguna forma podríem dir que el món gira entorn de la innovació. No hi ha àmbit teòric o pràctic que siga alié als processos d'innovació, de l'empresa al laboratori, de la gastronomia a l'esport, de l'art a la ciència, a més dels canvis tecnològics que es produeixen en matèria d'automoció, salut, energia, comunicació, etc. La innovació ens remet a assoliments en les ciències aplicades $i$ a resoldre problemes pràctics, igual que la invenció, que va des de la roda i l'escriptura fins a la impremta i el telèfon.

D'entrada associem la innovació a les ciències aplicades i els canvis en les ciències pures als desco- briments i creacions. No obstant això, el significat d'aquests conceptes s'ha anat modificant en el marc de la filosofia de les pràctiques científiques, i es poden trobar referències a la innovació en les ciències descriptives i descobriments en les ciències de disseny. Per exemple, Brown (2009) es refereix a la innovació conceptual en la física (Galileu) i en la química (Proust i Dalton), quan habitualment se'ls considerava descobridors. Brown sosté que és una manera d'abordar la dinàmica científica des d'una perspectiva menys rupturista i més gradualista. Nancy Nersessian (2009) descriu la innovació conceptual com aquells canvis que tenen lloc en alguns dels episodis més importants de la història de la física. En general, la idea de descobriment en les ciències descriptives s'entén com l'aportació de nous coneixements substantius que suposen una capacitat més àmplia d'explicació del món natural i social. I aquest és el sentit que Brown i Nersessian atorguen als exemples assenyalats, que consideren innovacions conceptuals.

No hi ha dubte que la idea d'innovació és polisèmica, per la qual cosa cal una anàlisi conceptual per tal d'extraure un denominador comú que en configure les característiques. Veurem que les definicions que indiquem a continuació, extretes d'Estany i Herrera $(2016)^{\mathbf{1}}$, encara que no s'haja expressat explícitament, fan al-lusió a les ciències aplicades o de disseny i algunes d'elles diferencien entre invenció i innovació.

- «Invenció» (creació d'una idea nova) i «innovació» (primera utilització d'una idea nova), ambdues estretament relacionades amb la paraula «tècnica» (Edgerton, 2013).

- Innovació és la generació, acceptació i implementació de noves idees, processos, productes i serveis (Shavinina, 2003).

1 Les referències d'aquestes definicions corresponen al llibre d'Estany i Herrera (2016), especialment al capítol 2. Per això s'ha tingut en compte el llibre de Shavinina, L.V. (ed.) (2003). The international handbook on innovation. Elsevier Science Ltd. 
- La innovació es defineix com un conjunt d'accions originals orientades a donar solucions a problemes no resolts prèviament, de manera única i creativa (Renzulli, 2003).

- «Invenció» és un avanç rupturista i «innovació» és l'actualització que experimenta (Florida, 1990).

- La invenció és l'origen creatiu d'un nou procés que facilita la innovació amb un impacte en els processos socials, econòmics i financers (Hindle, 1986).

- La innovació ocorre quan alguns individus produeixen solucions noves i membres rellevants d'aquest domini adopten aquestes solucions, considerant-les variacions valuoses de la pràctica habitual (Bailey i Ford, 2003).

- El terme «innovació» té dos significats diferents. El primer es refereix a la invenció, creació o descobriment que proporciona una cosa realment nova i útil. L'altre significat consisteix en l'adopció d'allò que és nou per a tu, tant si «tu» és un individu com si és una organització (Coates, 2003).

- Les innovacions són processos interactius que generen una cosa nova, transformadora i valuosa en entorns i sistemes determinats (Echeverría, 2017).

La característica comuna dels conceptes d'«innovació» $\mathrm{i}$ «invenció» com a conceptes integradors és la capacitat per a resoldre problemes pràctics. I en aquest punt abunden autors com els següents:

- Nickles (2003): la novetat ha de ser útil, ja que tant «innovació» com «descobriment» són termes d'èxit, termes que es refereixen a una cosa aconseguida.

- Sintonen (2009): La investigació aplicada és la cerca de coneixement on l'objectiu és, segons la caracterització autoritzada de l'OCDE de fa uns 30 anys, intentar utilitzar els resultats de la investigació bàsica o fins i tot descobrir nous coneixements que puguen tindre una aplicació pràctica immediata.

- Renzulli (2003) assenyala que els objectius de la ciència ens diuen que un propòsit principal és agregar nous coneixements a la comprensió de les condicions humanes, però en un camp de coneixement aplicat també hi ha un propòsit pràctic per a definir conceptes.

- Marinova i Phillimore (2003) posen l'accent en la innovació tecnològica, que distingeixen de la social, educacional i organitzativa.

A partir d'aquesta caracterització dels conceptes $\mathrm{d}^{\prime}$ «innovació» $\mathrm{i}$ «invenció», veurem què pot aportar el disseny a la comprensió dels processos d'innovació, des de la metodologia i l'epistemologia fins a allò que Nigel Cross anomena «cultura del disseny». En aquest sentit analitzarem alguns dels models de disseny especialment rellevants per als fenòmens innovadors.

\section{L'EMERGÈNCIA DEL DISSENY}

Les raons per les quals el disseny ha estat tan lligat a l'art i aplicat a entorns de la nostra vida quotidiana sense traspassar al món acadèmic són múltiples i segurament de diferent índole, és per això que podem dir que l'emergència del disseny és un fenomen multicausal al qual va unit la idea d'innovació, que també ha penetrat en camps nous.

La innovació industrial és un camp on el disseny és crucial, comprén des de mobles a cotxes, incloenthi la tecnologia relacionada amb la informàtica. El concepte més utilitzat en aquest àmbit és el de design thinking («pensament segons disseny»), que s'ha abordat des de diverses perspectives i s'ha aplicat a múltiples àmbits. Una de les primeres qüestions que s'ha plantejat és la seua definició, que no és fàcil des d'una visió essencialista, atesa la polisèmia. Hauria de veure's més aviat com un marc teòric

2 Malgrat les dificultats per traduir-lo al valencià, adoptarem l'expressió «pensament segons disseny». 
amb un denominador comú que seria un disseny a escala humana.

Lockwood (2009) defineix el pensament segons disseny com el procés d'innovació centrat en el factor humà que posa l'accent en l'observació, la col-laboració i l'aprenentatge ràpid. Es tracta d'aplicar la sensibilitat i els mètodes del dissenyador a la resolució de problemes en contextos diferents, és a dir: empresarials, comercials, de lideratge, de serveis públics i privats, etc. Un dels exemples aportats per Lockwood (2009), la roba d'esquiar, constitueix una mostra de pensament segons disseny. Un dels elements clau d'aquestes peces de roba és la protecció del fred, per la qual cosa els materials utilitzats per a fabricar-les són essencials per a la seua finalitat d'ús. L'èxit d'aquesta innovació es deu a la col-laboració de diversos professionals, especialment del dissenyador, l'enginyer i l'empresari. No és necessari que siguen tres persones diferents, però sí que aquestes tres perspectives convergisquen en la fabricació del producte. En aquest cas concret, segons conta Lockwood, ell mateix va aportar el disseny i la part comercial gràcies a que havia estudiat direcció d'empresa en la seua llicenciatura en la universitat. L'enginyer era imprescindible per a aportar els coneixements sobre materials i energia. Respecte als usuaris cal dir que, d'una banda, les noves peces les van provar els esquiadors habituals i, de l'altra, es va donar la circumstància que una de les persones que havia d'avaluar les possibilitats mercantils de la roba d'esquí era un aficionat a aquest esport. En resum, atés que qualsevol innovació implica aspectes diversos que no poden obviar-se, qualsevol novetat ha de ser el resultat de la participació dels diferents actors rellevants, en aquest cas: enginyers, dissenyadors $\mathrm{i}$ usuaris. Tot això sense deixar de costat la viabilitat econòmica en considerar costos i beneficis per a l'empresa que desenvolupe la iniciativa innovadora.

Vogel (2009: 5) considera que el pensament segons disseny pot cobrir la bretxa entre la producció intensiva centrada en el cost-benefici i la producció a escala humana. Fa referència al fet que la revolució industrial va fer possible fabricar en sèrie diversos productes, des de cotxes fins a llavadores, a més de mobles i edificis.
Enfront d'aquest fenomen van sorgir dos enfocaments principals: un centrat en la indústria i representat per Carnegie, Rockefeller, J. P. Morgan i Ford, i un altre que volia recollir la tradició del treball artesanal, representat per Charles Rennie Mackintosh, Frank Lloyd Wright i Gustav Stickley. Vogel (2009: 5) cita l'arquitecte Peter Behrens i l'escola Bauhaus com a exemples de pensament segons disseny que intenten realitzar una síntesi de les posicions tecnològiques i artesanes.

També Victor Papanek, en el seu llibre Diseño para el mundo real (2014), defensa el pensament segons disseny com un enfocament que aposta per la responsabilitat social en la producció. Acusa els dissenyadors que només tenen en compte els consumidors amb un alt potencial econòmic. Per tot això, és important la valoració de la satisfacció de l'usuari en relació a qualsevol tipus de producte, tenint en compte paràmetres com la usabilitat, l'accessibilitat, la comprensió i l'experiència.

Com a conclusió de l'emergència del disseny en el camp acadèmic, podem dir que els factors contextuals, dels sociopolítics als eticomorals, estan en el nucli del coneixement pràctic. Si s'aconsegueixen configurar marcs teòrics per a abordar aquests fenòmens tindrem una explicació racional dels elements que incideixen en la ciència i les conseqüències que tindran per a la societat. Un d'aquests marcs teòrics és el que es denomina «Ciència, Tècnica i Societat» (CTS), que, encara que habitualment no es relaciona amb el disseny, té moltes característiques sobre l'impacte de la ciència i la tècnica en els fenòmens socials que encaixen perfectament amb la idea de pensament segons disseny. Respecte a la connexió entre innovació i disseny, veiem que el coneixement pràctic, la resolució de problemes i els criteris per a un bon disseny formen el substrat en el qual convergeixen els processos d'innovació i pensament segons disseny.

\section{EL DISSENY EN L'ÀMBIT EPISTEMOLÒGIC}

Actualment, la idea de disseny ha arribat a l'epistemologia, un camp que, en principi, sembla 
allunyat de l'anàlisi de situacions pràctiques, atés que l'objectiu principal que persegueix, com a branca de la filosofia, ha sigut buscar els fonaments racionals de les nostres conviccions. No obstant això, el disseny aplicat a l'àmbit epistemològic pot proporcionar solucions als problemes de la ciència aplicada i una nova visió a l'epistemologia clàssica. Això requereix una clarificació conceptual de les expressions amb les quals ens referim a la relació entre disseny i epistemologia. ${ }^{3}$

Bengoa (2011) fa una sèrie de puntualitzacions respecte a l'abast de la ciència en l'aplicació pràctica que se li dona. La idea que l'epistemologia és la doctrina dels fonaments i dels mètodes del coneixement científic, segons Bengoa, no encaixa amb la varietat d'objectes que poblen el nostre camp de coneixement, per la qual cosa no pot haver-hi una sola epistemologia. En realitat, es refereix als objectes construits o artefactes, i es pregunta si es pot fer una epistemologia dels objectes construïts sobre la base d'altres paràmetres diferents dels tradicionals. En aquest sentit, fa una distinció entre epistemologia «per al» disseny i epistemologia «del» disseny. ${ }^{4}$ Sobre la primera diu que té a veure $a m b$ «una ciència del coneixement

3 Hi ha una dificultat afegida en traduir aquestes expressions, habitualment en anglés, al valencià o al castellà, encara que no és només un problema de traducció, com veurem a continuació. Precisament l'article de Bengoa (2011) «Distintos acercamientos epistemológicos: cinco enfoques sobre los objetos» està escrit directament en castellà i no per això deixa de sorgir la necessitat d'aclarir els sentits.

4 Aquesta distinció pot semblar només una qüestió lingüística, però és molt més que això. Un contrast que podria ajudar-nos a aclarir la distinció de Bengoa és el que s'estableix entre «ètica de la neurociència» $\mathrm{i}$ «neuroètica», encara que només com a metàfora, ja que la neurociència té una fonamentació uns resultats empírics que no té la teoria del disseny, almenys de moment. La primera estudia les implicacions ètiques dels progressos neurocientífics i de la pràctica dels professionals en aquest àmbit; la segona pren la neurociència com a base per a la comprensió i l'explicació de les decisions socials, morals i filosòfiques en sentit ampli. Una altra distinció anàloga és la que es produeix entre «filosofia de les ciències cognitives» $i$ «enfocament cognitiu en filosofia de la ciència». La primera es refereix a l'anàlisi filosòfica de les ciències cognitives, de la mateixa manera que ens referim a la filosofia de la física, de la química, de la biologia o de les ciències socials; la segona es refereix a models de ciència que estan ancorats en les ciències cognitives, un enfocament del qual R. Giere és un dels pioners. que ajude al dissenyador». De la segona diu que té a veure amb «una epistemologia que utilitze com a eina per a conéixer la realitat del propi disseny». Respecte a la primera, podríem dir que encaixa amb una epistemologia de la ciència aplicada. Respecte a la segona perspectiva, la definició sembla poc clara llevat que la interpretem com «una epistemologia que utilitze el propi disseny com a eina per a conéixer la realitat». La idea és que les teories de disseny constituïsquen un model per a l'epistemologia, tant en la seua funció de fonamentar les ciències pures com les ciències aplicades. Podria objectar-se que aquest plantejament és un cercle viciós; direm que és un cercle, però no viciós, sinó de retroalimentació entre coneixement, artefactes i disseny. A partir d'aquests dos sentits de la relació entre epistemologia i disseny analitzarem una sèrie de propostes que, encara que amb expressions diferents, incideixen en els dos sentits assenyalats per Bengoa.

Les expressions en llengua anglesa que reprodueixen els dos sentits de Bengoa són, d'una banda Epistemology of Design, que equivaldria a epistemologia «per al» disseny, i Design Epistemology, que equivaldria a epistemologia «del» disseny. La nostra proposta, seguint el que hem assenyalat en les notes 3 i 4 , seria que els dos sentits més rellevants de la relació entre epistemologia i disseny són: «epistemologia del disseny» $\mathbf{i}$ «epistemologia de disseny». La primera reflecteix el sentit d'epistemologia «per al» disseny i la segona el sentit d'epistemologia «del» disseny, encara que considerem que les expressions que proposem són les més adequades en llengua valenciana. No obstant això, com veurem a continuació, la majoria d'autors utilitzen aquestes dues expressions sense especificar les diferències entre elles.

D. Mahdjoubi (2003) en l'article «Epistemology of design» fa una classificació de disseny com a activitat, com a planificació i com a epistemologia. Com a activitat es refereix a la fase de pensar com serà el producte; com a planificació, a l'organització de les accions per a la realització del producte; i com a epistemologia, a la relació amb les metodologies sintètiques necessàries per a qualsevol canvi en les 
ciències aplicades diferents de les metodologies analítiques crucials per al desenvolupament de les iniciatives científiques. Mahdjoubi assenyala que la metodologia analítica ha mostrat deficiències o carències per a abordar la ciència aplicada, raó per la qual ha florit la metodologia sintètica, prenent l'epistemologia del disseny com una alternativa que pot pal-liar aquestes deficiències, especialment en camps com l'enginyeria.

Amb el títol «Design Epistemology», D. Karabeg (2012) proposa que el disseny siga l'alternativa a la tradició. Això significa un qüestionament de l'epistemologia tradicional que no encaixa amb una aposta per la innovació com a eix central de la investigació científica. La idea central és el que anomena postulating an epistemology, és a dir, plantejar quin significat li donarem a «epistemologia», que vaja més enllà de l'epistemologia entesa com la base sobre la qual s'assente la cerca de la veritat i del significat de les coses.

Veiem que el sentit de Karabeg no és diferent del de Mahdjoubi, malgrat que el primer el denomina design epistemology, mentre el segon el designa epistemology of design. Per tant, Karabeg reforça una perspectiva en el marc de la investigació acadèmica que és una alternativa als enfocaments tradicionals. Si pensem l'alternativa per a la ciència pura, constituiria el que denominem «innovació epistemològica», que implicaria tant noves formes de representació del coneixement com canvis en els valors epistèmics o, almenys, en la seua priorització. En aquest sentit, i sent fidels a Karabeg, aquesta innovació epistemològica s'hauria de fer d'acord amb els models de disseny. La proposta sembla indicar que, a diferència de l'epistemologia tradicional, la de disseny és més dinàmica i permet incorporar nous elements sorgits en el curs de la investigació.

Respecte a les característiques de l'epistemologia de disseny, Karabeg (2012) assenyala com especialment rellevant el que denomina wholeness, en el sentit de totalitat i integració, que defineix com «la qualitat que caracteritza a un organisme sa i perfectament desenvolupat, o un mecanisme complet i immaculadament funcional: totes les parts funcionen bé i en sinergia entre elles, i compleixen el seu propòsit dins de la totalitat, perquè aquesta puga funcionar bé i complir els propòsits, fins i tot en àmbits més grans» (Karabeg, 2012: 3). A conseqüència d'això tindríem la «transdisciplinarietat», que es concretaria en la knowledge federation, és a dir, en una federació de coneixements i disciplines amb la finalitat que qualsevol fenomen poguera abordar-se des de diverses perspectives, imitant un calidoscopi.

Per les característiques que Mahdjoubi i Karabeg atribueixen a la relació entre epistemologia i disseny, sembla que allò fonamental és una alternativa a la tradició i a l'epistemologia analítica i una aposta per l'epistemologia sintètica, que correspon a la de disseny, en el sentit d'un acostament a la ciència amb el marc mental del dissenyador.

Un altre dels conceptes relacionats amb l'epistemologia del disseny és la Design Theory, que aborda L. E. Östman (2005) en l'article «Design theory is a philosophical discipline - Reframing the epistemological issues in design theory». Segons Östman, la teoria del disseny no és una ciència social ni una ciència natural, sinó una disciplina filosòfica que pren el pragmatisme com a marc que proporciona raons per a la teoria del disseny. No es tracta de fixar el coneixement a una simple veritat, sinó d'abordar problemes i promoure la comprensió a través de la clarificació, el raonament i la crítica. Aquestes afirmacions constitueixen la base de la seua proposta, centrada en el coneixement per a la resolució de problemes, no per a assolir la veritat, o almenys, no sols per a això, ni en primer terme.

Per tant, podem dir que el nucli de la relació entre epistemologia i disseny, diguem-ne «epistemologia del disseny» $\mathrm{o}$ «epistemologia de disseny», consisteix en pensar amb la mentalitat del dissenyador, prenent com a marc el pensament segons disseny. De fet, la crítica a l'epistemologia analítica no és nova i comença en la dècada dels cinquanta, encara que és amb Thomas Kuhn (1962) i La estructura de 
las revoluciones científicas quan es marca un canvi de paradigma en allò que es consideraven els pilars de la denominada «concepció heretada». La sociologia de la ciència i la sociologia del coneixement van seguir el període historicista, i ara estem en l'enfocament cognitiu de la ciència i la tecnologia, sense que això supose que cap d'aquestes línies de pensament haja desaparegut, sinó que coexisteixen i, en certa forma, es complementen. Podem considerar que l'epistemologia de disseny recull part de les crítiques a l'epistemologia analítica amb la mirada posada en la ciència aplicada i en la resolució de problemes.

\section{LA SIMULACIÓ COMPUTACIONAL COM A INNOVACIÓ EN EL MÈTODE CIENTÍFIC}

La simulació ha sigut la gran oblidada de la metodologia de la ciència per part dels filòsofs emmarcats en el que s'ha anomenat la «concepció heretada». Des de Hempel a Kuhn s'ha analitzat què són les teories, les lleis, l'explicació, buscant com és el coneixement que aquestes formes de representació suposen per a la nostra comprensió del món. No obstant això, ara la pregunta és: què sabem més del món quan tenim una simulació sobre algun dels seus processos? Per això és important abordar la simulació computacional, tant en el seu marc teòric, molt influenciat per la física i les matemàtiques, com en la seua part pràctica, com és l'exemple de les allaus de neu. En aquest sentit, l'epistemologia de disseny és un bon marc per a innovar en els models metodològics i no hi ha dubte que la simulació computacional s'emmarca adequadament en aquest context.

La simulació computacional com a innovació metodològica comporta dos processos: la creació de models i el treball pròpiament dit de simulació per mitjà d'ells. La simulació computacional està associada a l'ús de l'ordinador en el treball científic. La simulació i la prèvia creació de models és útil per a afrontar problemes que desborden la capacitat humana a mà nua o per a implementar experiències. Expressat d'una altra manera, l'ús de la modelització és una eina imprescindible per a dur a terme eficaçment la simulació computacional.

En les ciències de la naturalesa és necessari afrontar problemes inaccessibles a nivell humà, per exemple, de naturalesa astronòmica a gran escala on, encara que sorprenga, paradoxalment és necessari conéixer xicotets detalls: un sistema solar de tres cossos té essencialment els mateixos problemes dinàmics que un més gran; no obstant això, és molt més fàcil en principi treballar amb tres cossos que amb un nombre major. A aquest resultat, que no és obvi, s'hi ha arribat després de segles de maduració científica. Si ens detenim en aquesta idea, trobem el germen dels models i, com a associada, apareix la simulació.

Així, en moltes ocasions els fenòmens a escales no humanes (les dimensions impossibles) són candidats a ser tractats en el context d'aquesta heurística. Però no sols succeeix en fenòmens d'aquest tipus, també problemes d'índole més delicada, ja que ens afecten en qualitat d'éssers humans.

La modelització com a procés analític per excel-lència s'usa en l'estudi de la matèria, en les ciències d'estructura matemàtica i en les ciències de la vida. Els models es desenvolupen segons el pensament matemàtic que s'adequa a la mena de raonament de la física, descrivint les observacions descarnadament, desproveint-les d'allò accessori, actuant sobre les característiques essencials o estructurals i cosificant-les.

En aquest sentit, una bona teoria descriu un ampli domini de fenòmens a partir d'uns models senzills i efectua prediccions que poden ser sotmeses a prova, la qual cosa atorga fiabilitat.

La simulació computacional permet abordar problemes i resoldre qüestions que, amb l'epistemologia clàssica, centrada en models molt rígids com el concepte de teoria o l'explicació hipoteticodeductiva, centrals en l'empirisme lògic, no encaixaven, atesa la complexitat de molts fenòmens. Això no significa que en la pràctica els científics s'hagen limitat a una 
simplificació del mètode científic, sinó que han tingut en compte alternatives inesperades a fi de provar idees. Casos com els models fisicomatemàtics i la simulació en les ciències humanes i socials en són exemples.

\section{La simulació computacional sustentada en models fisicomatemàtics}

La simulació computacional estructurada sobre la base de models fisicomatemàtics és un recurs metodològic-heurístic habitual en les últimes dècades. De fet, s'ha consolidat en el camp de les ciències (incloses les ciències computacionals i les ciències de la vida) i les tecnologies i enginyeries a partir de la segona meitat del segle $\mathrm{xx}$.

El model, com que és un intermediari entre l'observador i l'objecte ${ }^{5}$ observat, proporciona informació rellevant per a l'elaboració del coneixement (sense caure en la identificació del model amb l'objecte modelat); atés que el món és independent del que en podem dir o pensar, i com ja queda prou subratllat, el model és una idealització per excés —o per defecte- de la realitat. En tots els casos, no passa de ser una racionalització o un sistema lògic coherent (formulat en llenguatge matemàtic).

\section{La simulació computacional en les ciències socials i humanes}

Les denominades «humanitats» tenen un abordatge discursiu no matemàtic, els estudis i anàlisis se solen efectuar mitjançant el llenguatge natural i utilitzant cites i comentaris de les cites que van aprofundint gradualment en el contingut i el desenvolupen.

Aquest mètode de treball no és adequat per a l'anàlisi matemàtica dels objectes propis d'estudi que presen ta: en conseqüència, no s'ha de plantejar en termes d'equacions o en general de la lògica matemàtica, i

5 La veu «objecte» s'usa en sentit ampli i designa fenòmens, processos, etc., tant del món físic conegut com imaginaris. Se sol construir a partir de preguntes i altres elements intermediaris. en aquest sentit la gran varietat d'objectes d'estudi no és modelitzable matemàticament i per tant no són materials d'estudi viables per a la realització de simulacions computacionals. Aquesta inadequació tal vegada podria ser salvable almenys en algunes situacions d'investigació, utilitzant un pas intermedi, una espècie de pont.

La col-laboració entre historiadors, per exemple, i estudiosos dels moviments de partícules en un fluid (moviment brownià) pot resultar productiva. En un intent de modelitzar conflictes socials s'estan contrastant dades històriques precises amb dades proporcionades pels experts en moviment brownià, $i$ s'estan trobant unes certes pautes de comportament en els moviments humans en diferents tipus de conflictes socials. Presenten unes certes analogies amb les partícules en moviment brownià representables matemàticament en termes de equacions i per tant són susceptibles de ser simulades computacionalment. De fet, ja s'està començant a produir literatura ad hoc. No convé avançar-se, això és només l'inici, el futur ens donarà el desenvolupament.

LA INNOVACIÓ TECNOLÒGICA EN LA TASCA CIENTÍFICA La tecnologia que caracteritza el nostre temps, amb la impressionant potència que es retroalimenta de continu i que concerneix subjectes de tota condició, constantment força noves consideracions i maneres de relació entre els éssers humans i el món, en les quals sorgeixen dubtes i preguntes: a què es deu la fascinació per l'entorn tecnològic que en major o menor grau compartim i per l'afany de solucionar que aquest entorn ens proporciona? Aquest entorn, construït linealment de manera acumulativa, donem per descomptat quasi sense reflexió que realitza una aportació positiva a la nostra existència. És la pura atracció emocional per les coses noves? Intuïm que hi ha alguna cosa més? Un món nou es presenta al nostre abast.

Les persones més escèptiques es pregunten si la sobreexposició a la innovació tecnològica (que porta 
associada una hipervaloració d'aquesta innovació) està, tal vegada, deixant de costat el coneixement reflexiu, la ciència, que s'ha considerat tradicionalment com el progrés real, o si és una forma nova i autèntica d'aquest mateix coneixement.

Potser per això busquem dotar d'emoció (o d'aparença d'emoció) els anomenats ad hoc robots «emocionals», almenys en certa manera, és a dir, busquem que s'assemblen d'alguna manera a nosaltres.

L'exemple que analitzem a continuació entra de ple en un dels objectius del disseny, a saber: resoldre problemes pràctics com és el cas de les allaus de neu.

\section{Un exemple de simulació computacional: les allaus de neu}

Una allau de neu és una massa de neu i gel que descendeix pel vessant d'una muntanya abruptament a gran velocitat, originant un remolí d'aire (el vent de l'allau) i arrossegant tot el que troba al seu pas: terra, pedres, trossos de roques, etc.

Aquest fenomen s'origina per l'evolució de les capes de neu que se superposen en les muntanyes a causa dels episodis de successives nevades, que depenen primordialment de les condicions meteorològiques. La coberta de neu formada en etapes successives per superposició de capes de neu de diferent consistència i diferent estabilitat té unes capes més inestables que, quan es produeixen episodis de vent fort $\mathrm{i}$ fases de desglaç, donen lloc a les allaus.

Aquestes allaus i els materials que arrosseguen al seu pas poden causar moltes destrosses; en aquest sentit, és convenient analitzar els mecanismes per a organitzar la protecció de persones i béns.

L'interés per caracteritzar i delimitar el fenomen de les allaus ve des de lluny: els pobles de muntanya a principis del segle $\mathrm{xx}$ descrivien diferents tipus d'allaus que, pel seu propi interés, classificaven primer per a predir el seu recorregut i l'abast dels danys que podien produir i també per a reconéixer les condicions en què era previsible que s'originara alguna allau i actuar preventivament adaptant les construccions i la vida en general a aquestes circumstàncies per a protegir-se adequadament.

Per a organitzar la simulació numèrica d'aquest procés previ al treball computacional, cal determinar amb precisió les característiques del fenomen físic i formalitzar-lo. La neu en interacció amb l'aire forma una espècie de fluid de comportament complex difícil de caracteritzar, i per això es recorre a les equacions més potents típiques de la mecànica de fluids, les de Navier-Stokes, en aquest cas adaptades a la naturalesa de l'allau. Per a aconseguir les primeres aproximacions es considera un comportament mitjà, sense entrar en alguns detalls dels quals, encara que són importants, es pot prescindir sense impedir un estudi fiable sobre la formació d'una allau amb una antelació acceptable.

Els termes complementaris propis de les allaus s'introdueixen en aquestes equacions de Navier-Stokes i les modifiquen en la seua estructura matemàtica típica i, per tant, influeixen en la naturalesa de les solucions. Alguns elements concrets de les equacions són crucials per a descriure el comportament del lliscament.

L'observació de les allaus reals i les seues simulacions computacionals estan en fase de contrastació i és un camp d'estudi i investigació molt actiu que força una relació interdisciplinària intensa dels agents intervinents: enginyers, físics, matemàtics, científics computacionals i experts en allaus de neu en alta muntanya. Aquest repte desperta interés a nivells diferents, no sols al nivell científic per les pures matemàtiques i físiques implicades, sinó també en altres camps, com l'esportiu, el geològic i el mediambiental, per exemple.

La simulació de les allaus de neu no sols persegueix un millor coneixement del funcionament de la naturalesa, sinó que té un propòsit pràctic. En aquest sentit, es troba una utilitat addicional dels models i mètodes matemàtics utilitzats tradicionalment en la física, en la simulació i en general en aquest procediment de treball amb el propòsit de 
Figura 1 Representació gràfica del mètode científic segons McCrory (1974: 160).

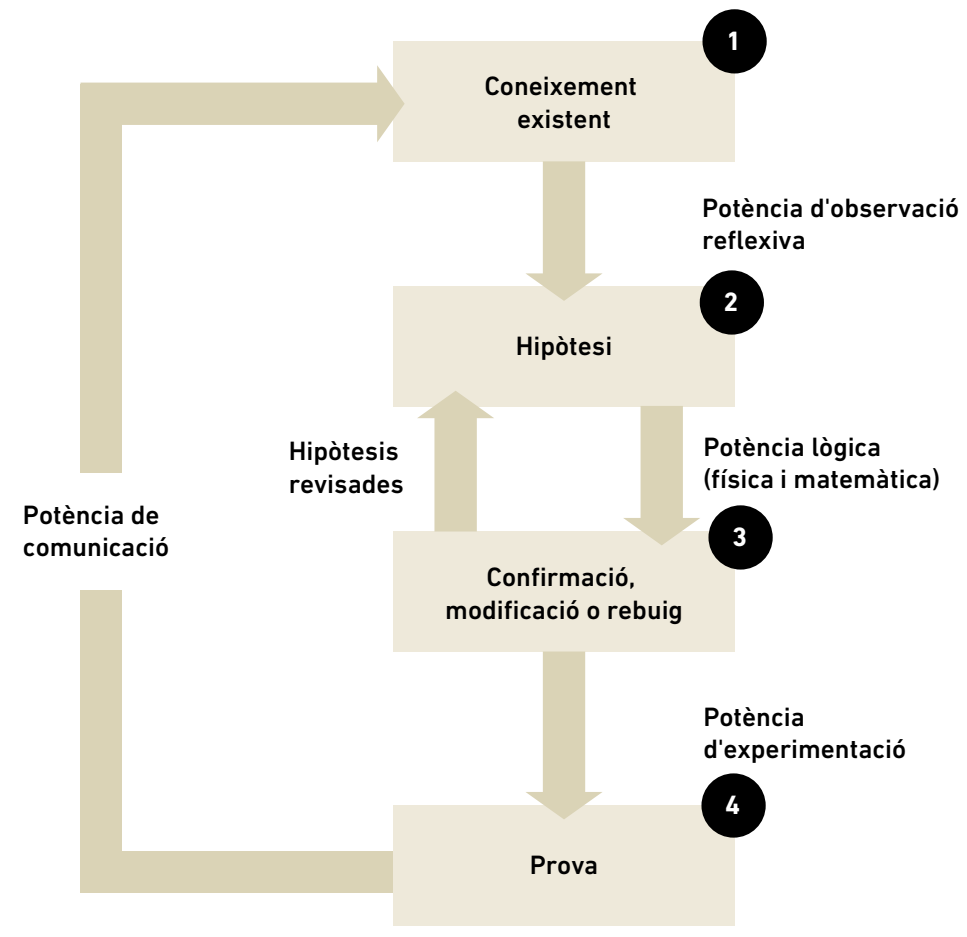

resoldre amb criteris propis del pensament segons disseny.

\section{MODELS METODOLÒGICS DE DISSENY}

Amb la idea de buscar una alternativa a l'epistemologia analítica estan els models metodològics de disseny com un dels camps en què el disseny incideix en la metodologia de les ciències aplicades. L'esquema clàssic del mètode científic (Figura 1) consisteix a provar una hipòtesi. Si la predicció es compleix, el coneixement obtingut s'afig al saber general. En la pràctica, els processos metodològics són més complexos i consten de diverses etapes, sobretot quan s'afronta una situació problemàtica nova o quan cal canviar de procediment perquè no s'arriba a cap mena de resultat vàlid. No obstant això, l'esquema de la Figura 1 continua reflectint la idea general de la contrastació d'hipòtesi. Malgrat això, els científics que treballen en les ciències aplicades han qüestionat que l'esquema clàssic fora el més adequat per a aquests àmbits científics. Així sorgeixen les metodologies pròpies de les ciències de disseny.

Les ciències de disseny són el resultat d'un procés de cientificació i mecanització de les arts en el sentit d'habilitats i activitats pràctiques. Simon (1996) assenyala que el model tradicional de ciència ofereix una imatge enganyosa de camps com l'enginyeria, la medicina, l'arquitectura, l'economia, l'educació, etc., que estan interessats en el «disseny», en el sentit 
Figura 2 Representació gràfica del mètode de disseny segons McCrory (1974: 162).

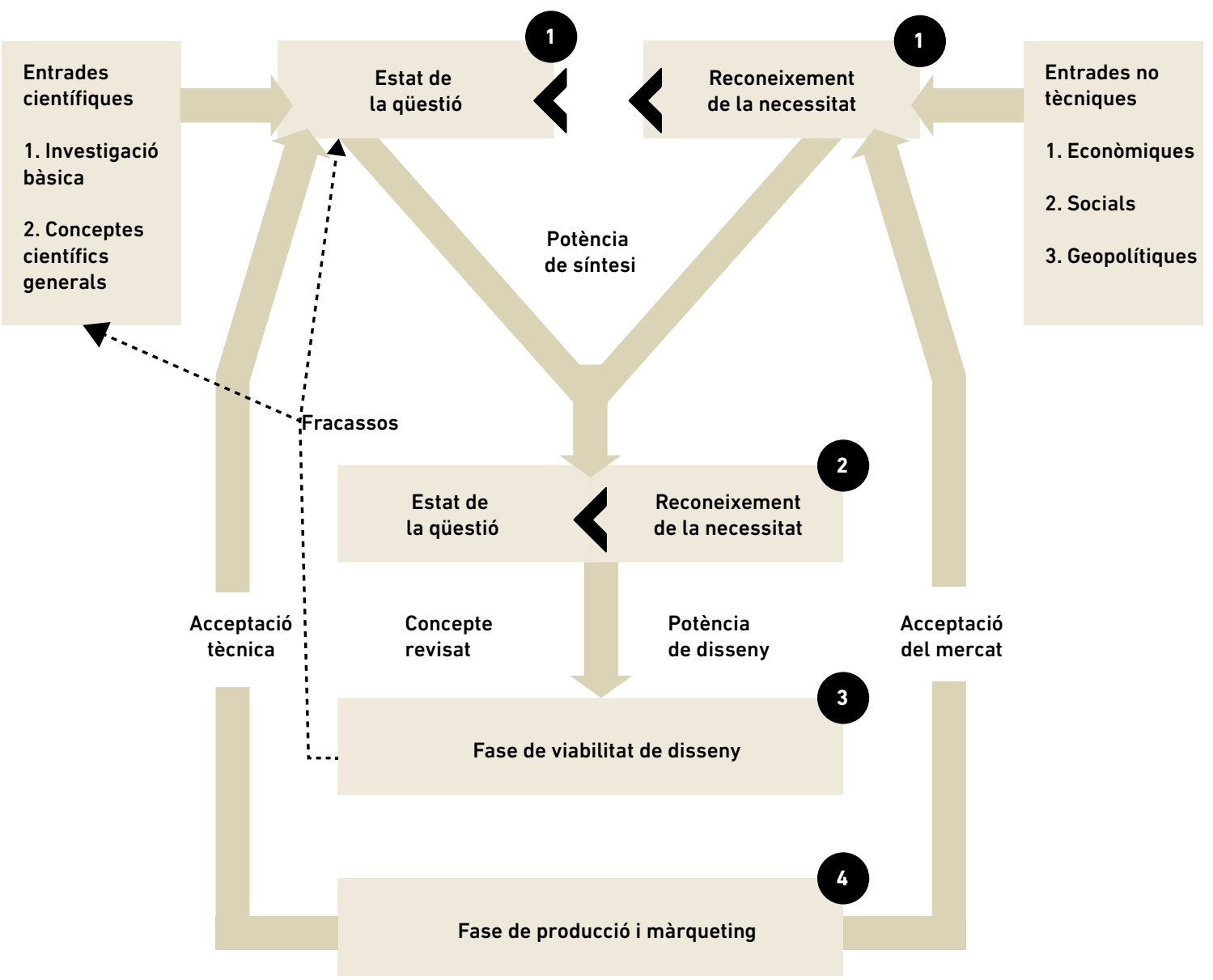

de propòsit o meta a assolir, és a dir, no tenen com a objectiu saber com són les coses, sinó com han de ser per als propòsits assignats.

Indiscutiblement, els enginyers no són els únics dissenyadors professionals. L'activitat intel-lectual que produeix artefactes materials no és fonamentalment diferent a la de prescriure fàrmacs a un pacient, programar un nou pla de vendes per a una companyia o una política d'assistència social. El disseny, així construït, és el nucli de la formació de les ciències aplicades, fruit de la professionalització de l'antic treball artesanal. Les escoles d'enginyeria, així com les escoles de lleis, arquitectura, educació, medicina, etc., orbiten al voltant del procés de disseny, institucionalitzant aquestes disciplines.

S'han proposat diversos models de metodologia enginyera, entre els quals podem assenyalar, a tall d'exemple, els següents: Gerald Nadler (1967), M. Asimov (1962), A. D. Hall (1974) i R. J. McCrory (1974), entre altres. 
Malgrat les diferències, en tots els models es donen una sèrie de característiques i posicionaments sobre la metodologia de disseny d'acord amb les finalitats pràctiques. Així, Nadler assenyala que dissenyar consisteix en engiponar els processos a fi d'obtindre resultats útils, utilitzant el coneixement, les lleis i les teories desenvolupades a partir de la investigació en ciències bàsiques o descriptives. Asimov considera que el disseny enginyer és una activitat dirigida a satisfer necessitats humanes, particularment aquelles que tenen a veure amb els factors tecnològics de la nostra cultura. Hall distingeix tres dimensions en tot sistema enginyer: la dimensió temps; el procediment per a resoldre un problema; i el cos de fets, models i procediments que defineixen una disciplina, professió o tecnologia. Si bé podem trobar l'equivalent d'aquestes tres dimensions en els altres models, és la tercera dimensió la que és especialment interessant per a abordar la identitat d'una disciplina professionalitzant. La definició d'una disciplina dona entitat a una sèrie de professions que actualment s'han institucionalitzat, convertint-se en estudis universitaris que ajuden a comprendre aquest procés d'institucionalització.

Finalment, McCrory entén que la funció del disseny no és originar el coneixement científic, sinó utilitzar-lo a fi que el resultat siga una creació útil. En aquest sentit, la funció del dissenyador pot ser considerada similar a la de l'artista, ja que dona lloc a noves creacions. Cal ressaltar la idea que en la concepció d'un disseny convergeixen els coneixements científics (estat de la qüestió) i les necessitats que constitueixen l'entrada no tècnica i que corresponen als factors socials, econòmics, geopolítics, etc.

En aquest model no està inclòs el disseny en l'entrada no tècnica, però tindria sentit afegir-lo i tindre'l en compte en la segona fase de concepció del disseny. En aquesta fase és quan es pensa en el que volem dur a terme, siga un artefacte, un fàrmac, un avió o un pla d'estudi. És especialment important tindre en compte el pensament segons disseny amb la finalitat que s'adeqüe als futurs usuaris.

\section{LA CULTURA DEL DISSENY ENTRE LES CIÈNCIES I LES HUMANITATS}

A partir d'allò que hem dit sobre innovació i l'impacte que té en l'epistemologia i metodologia de la ciència, la denominada per Cross «cultura del disseny» sembla el marc més apropiat per a abordar els processos d'innovació i invenció, un àmbit en el qual convergeixen elements teòrics i pràctics, donant una nova perspectiva integradora de les ciències $i$ les humanitats.

En la seua obra Designerly ways of knowing, Cross (2006) considera el disseny com una forma de coneixement enllaçat amb l'epistemologia de disseny i el pensament segons disseny. Una de les idees centrals de la seua proposta és que el disseny constitueix la tercera cultura que s'afegiria a la de les ciències i les humanitats, per la qual cosa hauria de formar part de l'educació, i no sols per a determinades professions, sinó com un dels pilars de la formació general.

Així, igual que hi ha maneres d'acostar-se als fenòmens des de les humanitats i des de les ciències, que podríem qualificar de maneres de pensar humanístiques i científiques, també podem abordar els fenòmens partint del disseny en el sentit de «formes de conéixer basades en el disseny». Cross assenyala algunes diferències entre aquestes tres cultures respecte a l'objecte d'estudi, al mètode i als valors. En el cas del disseny, l'objecte d'estudi és el món artificial; entre els mètodes cita la formació de patrons; i com a valors predominants, la practicitat, l'empatia i l'adequació als propòsits que es volen aconseguir.

Altres característiques rellevants de les formes de conéixer disseny són: la manipulació de codis no verbals en la cultura material, la connexió entre fer i pensar i la rellevància de les maneres de cognició icòniques (2006: 11). I quant a les habilitats del disseny, assenyala les següents: resoldre problemes mal definits, adoptar estratègies centrades en buscar solucions i utilitzar el raonament abductiu i mitjans no verbals i gràfics per a representar el coneixement (2006: 20). Totes aquestes característiques estan en el nucli dels processos d'innovació i invenció. 
Distingeix tres formes de connexió entre els conceptes de ciència i disseny, que corresponen a sentits diferents:

a) Disseny científic (scientific design) és el disseny, siga en el camp que siga, encara que amb preferència en el disseny industrial, per al qual el dissenyador recorre al coneixement científic.

b) Ciències de disseny (design sciences) són les ciències l'objectiu de les quals no és descriure el món, sinó transformar-lo, com ara les enginyeries, la medicina o les ciències de l'educació i de la informació.

c) Ciència del disseny (design science) és el cos de teories del disseny per a portar a la pràctica un producte determinat a través del mètode científic.

Cal assenyalar que el mateix Cross vol deixar clar que no té el mateix significat science of design que design science. Ens podem plantejar si les distincions proposades per Cross són fructíferes per a la clarificació del complex i ampli camp del disseny. La primera cosa que caldria dir és que, en la pràctica, és a dir, en qualsevol activitat en la qual el disseny estiga implicat, aquests conceptes s'entrellacen i convergeixen en l'activitat, el producte o el procés de disseny. No obstant això, precisament per ser un camp relativament nou, almenys en el món acadèmic, és important una primera anàlisi conceptual.

Podem dir que la cultura del disseny té com a finalitat situar el marc en el qual tenen lloc moltes de les idees que es van desenvolupant en l'article. De fet, la mateixa idea del paper que el disseny juga en la innovació tindria poc sentit sense aquest marc general. A més, les tres formes de connexió entre ciència i disseny que assenyala Cross (disseny científic, ciències de disseny i ciència del disseny) donen sentit als objectius $i$ al desenvolupament que se' $n$ fa.

\section{CONCLUSIÓ}

Hem vist que el disseny impregna tots els àmbits científics i culturals de la conceptualització del món natural i social, encara que a vegades oblidem que l'àmbit social forma part de l'àmbit natural. Constitueix una nova perspectiva amb la qual ens podem aproximar a la complexitat de tots els fenòmens dels què som conscients. Si el món gira entorn de la innovació, no hi ha dubte que el pensament segons disseny és una base perquè en els processos d'innovació els interessos i capacitats humanes prevalguen per damunt dels interessos econòmics. Aquestes conclusions, encara que concises, són de gran importància per al pensament actual i per a la filosofia en la seua funció de metaconceptualització del saber. Des del punt de vista dels reptes que la humanitat té plantejats en l'actualitat, la versió pràctica del coneixement i l'afany per la resolució de problemes tindrà conseqüències per al disseny de les institucions.

\section{REFERÈNCIES BIBLIOGRÀFIQUES}

Asimov, M. (1962). A philosophy of engineering design. A Contributions to a Philosophy of Technology (p. 150-157). Dordrecht: Springer.

Bengoa, G. (2011). Distintos acercamientos epistemológicos: cinco enfoques sobre los objetos [Seminari]. Facultad de Arquitectura, Diseño y Urbanismo, UBA Universidad de Buenos Aires.

Brown, H. I. (2009). Conceptual comparison and conceptual innovation. A J. Meheus i T. Nickles (ed.), Models of discovery and creativity (p. 29-41). Dordrecht: Springer.

Cross, N. (2006). Designerly Ways of Knowing. Londres: Springer.

Dalsgaard, P. (2014). Pragmatism and design thinking. International Journal of design, 8(1).

Echeverría, J. (2017). El arte de innovar. Naturalezas, lenguajes, sociedades. Madrid: Plaza y Valdés.

Edgerton, D. (2013). Quoi de neuf? Du rôle des techniques dans l'histoire globale. París: Éditions du Seuil.

Estany, A. i Herrera, R. M. (2016). Innovación en el saber teórico y práctico. Londres: College Publications. 
Hall, A. D. (1974). Three dimensional morphology of systems engineering (1969). Contributions to a Philosophy of Technology.

Karabeg, D. (2012). Design Epistemology. Information, 3, 1-x.

Kuhn, T. (1962) La estructura de las revoluciones científicas. Mèxic: Fondo de Cultura Económica.

Lockwood, T. (ed.) (2009). Design Thinking. Integrating Innovation, Customer Experience, and Brand Value. Nova York: Allworth Press.

Mahdjoubi, D. (2003, juny). Epistemology of Design. A Integrated Design and Process Technology (p. 1-5). IDPT.

McCrory, R. J. (1974). The Design Method-A Scientific Approach to Valid Design. En F. Rapp (ed.), Contributions to a Philosophy of Technology, (p. 158-173). Dordrecht: Reidel.

Nadler, G. (1967). An investigation of design methodology. Management science, 13(10), B-642.

Nersessian, N. (2009). Conceptual change: creativity, cognition, and culture. A J. Meheus y T. Nickles (ed.), Models of discovery and creativity (p. 127-165). Dordrecht, Springer.

Niiniluoto, I. (1993). The aim and structure of applied research. Erkenntnis, 38, 1-21.

Östman, L. E. (2005). A Pragmatist Theory of Design. The Impact of the Pragmatist Philosophy of John Dewey on Architecture and Design [tesi doctoral]. School of Architecture Royal Institute of Technology. Stockholm.

Östman, L. E. (2005). Design theory is a philosophical discipline-Reframing the epistemological issues in design theory. Design System Evolution.

Papanek, V. (2014). Diseño para el mundo real. Ecología humana y cambio social, $2^{\text {a }}$ edición en castellano. Barcelona: Pol·len Edicions.

Shavinina, L.V. (ed.) (2003). The international handbook on innovation. Elsevier Science Ltd.

Simon, H. (1996 [1969]). The science of the artificial. Cambridge (MASS): MIT.

Vogel, C. M. (2009). Notes on the evolution of design thinking: A work in progress. A T. Lockwood (ed.) (2009), Design thinking. Integrating innovation, costumer experience, and brand value. Nova York: Allworth Press.

\section{NOTA BIOGRÀFICA}

\section{Anna Estany}

Doctora en Filosofia per la Universitat de Barcelona i Master of Arts per la Indiana University (EUA). Actualment és catedràtica de Filosofia de la Ciència en el Departament de Filosofia de la Universitat Autònoma de Barcelona. Constitueixen les seues línies d'investigació els models de canvi científic, l'enfocament cognitiu en filosofia de la ciència i de la tecnologia i la filosofia de les ciències de disseny.

\section{Rosa M. Herrera}

Va cursar els seus estudis de Física en la Universidad Autónoma de Madrid. És doctora en Física per la Università degli Studi di Roma Tor Vergata. És membre del grup «Pensamiento Matemático» de la UPM i de la European Society for Astronomy in Culture. Treballa en sistemes dinàmics de baixa dimensió, mecànica celeste i astrofísica gravitacional, en el marc d'un consorci internacional europeu per a desenvolupaments en astrodinàmica, en col·laboració amb una agrupació interuniversitària italiana. 


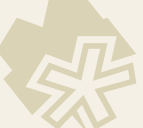

